\title{
CVD carbon powders modified by ball milling*
}

\author{
TOMASZ KAŹMIERCZAK ${ }^{\dagger}$, WitOLd KACZOROWSKI, PIOTR NiEDZIELSKI \\ Lodz University of Technology, Faculty of Mechanical Engineering, Institute of Materials Science and Technology, \\ Lodz, Poland
}

\begin{abstract}
Carbon powders produced using a plasma assisted chemical vapor deposition (CVD) methods are an interesting subject of research. One of the most interesting methods of synthesizing these powders is using radio frequency plasma. This method, originally used in deposition of carbon films containing different $\mathrm{sp}^{2} / \mathrm{sp}^{3}$ ratios, also makes possible to produce carbon structures in the form of powder. Results of research related to the mechanical modification of these powders have been presented. The powders were modified using a planetary ball mill with varying parameters, such as milling speed, time, ball/powder mass ratio and additional liquids. Changes in morphology and particle sizes were measured using scanning electron microscopy and dynamic light scattering. Phase composition was analyzed using Raman spectroscopy. The influence of individual parameters on the modification outcome was estimated using statistical method. The research proved that the size of obtained powders is mostly influenced by the milling speed and the amount of balls. Powders tend to form conglomerates sized up to hundreds of micrometers. Additionally, it is possible to obtain nanopowders with the size around $100 \mathrm{~nm}$. Furthermore, application of additional liquid, i.e. water in the process reduces the graphitization of the powder, which takes place during dry milling.
\end{abstract}

Keywords: carbon powder; CVD; milling; Taguchi method

(C) Wroclaw University of Technology.

\section{Introduction}

The concept of carbon powders includes a number of forms and types of carbon, such as nanotubes, fullerenes, diamond crystals, graphite and amorphous carbon. Among the methods used to their production we can mention CVD (Chemical Vapor Deposition) or HTHP (High Teperature High Pressure) as well as mechanical methods based mostly on milling in specifically designed mills.

Last decade belongs to nanomaterials among which carbon materials play a crucial role. Research on nanodiamonds, methods of their synthesis and properties has been carried out for years [14]. It turned out that the best way of obtaining them is based on the detonation methods. Crystalline nanopowders are regarded to have more and more applications, especially those in medicine are the most spectacular ones [4]. Equally interesting

\footnotetext{
${ }^{*}$ This paper was presented at the $4^{\text {th }}$ National Conference on Nano- and Micromechanics (KKNM) Conference, Wrocław, Poland, 8 - 10 July, 2014.

†E-mail: kazmierczak.tomasz@gmail.com
}

are the studies on nanotubes and fullerenes, where the methods of synthesis based on microwave [5] and arc plasma [6] dominate. Those technologies are used in the production of other types of carbon powders including nanodiamonds.

In comparison to nanostructures mentioned above, the interest in amorphous carbons is marginal. However, for the last few years the number of publications related to this topic has been increasing and included results proving that this type of powders may find their future in biomedical applications [7-9].

One of the methods of producing amorphous carbon powders is synthesizing them in chemical process using microwave and radio frequency induced plasma. Controlling the process parameters allows obtaining powders with varying properties which include phase composition. However, this technique does not allow controlling the particle size in very wide range of values. Typical diameter of individual grains is within a range of tens and hundreds of micrometers and they are also not very uniform in shape. 
Applying an additional step in the process of carbon powder production in a form of mechanical milling enables the control over the size of particles, which can be improved using statistical methods, like the one proposed by Taguchi [10].

This paper includes the results of the analysis of the influence of particular milling conditions on the possibility of reducing the size of carbon powder particles. It also addresses the impact of milling conditions on graphitization of a modified powder and using PCA (Process Control Agent) for reducing this effect.

\section{Experimental}

\subsection{Carbon powders preparation and characterization}

The powders were synthesized using radio and microwave frequency plasma assisted chemical vapor deposition (MW/RF PACVD). In order to provide the highest level of repeatability, the system was equipped with a number of control components. Continuous control included parameters, such as time of the process, pressure in the chamber, the amount of gases delivered to the chamber, the temperature of refrigerant cooling the RF electrode and chamber walls, radio frequency power, microwave power, MW and RF power reflected. Each synthesis process lasted for 2 hours during which RF and MW powers were $500 \mathrm{~W}$ and $600 \mathrm{~W}$, respectively. Methane was used as a source of carbon which was dosed at $190 \mathrm{sccm}$ rate at $130 \mathrm{~Pa}$ pressure.

After finishing of plasmochemical processes, powder samples were collected from previously selected spot on the electrode for mechanical modification and further material investigations.

Mechanical modification was carried out in a planetary ball mill Retsch PM100 using zirconium oxide bowl and balls $1 \mathrm{~mm}$ in diameter. Milling was performed for 1,5 and 10 hours at various speeds: from 100 to $600 \mathrm{rpm}$. In order to reduce the effect of agglomeration, PCA (process control agent) in form of distilled water was added.

The shapes of both initial and modified powders were analyzed using scanning electron microscope
JEOL JSM-6610LV. It also enabled the estimation of the size of particles larger than $2.5 \mu \mathrm{m}$. The size of smaller particles was measured with DLS (Dynamic Light Scattering) technique using DynaPro Nanostar by Wyatt Technology. For the test, samples were prepared in a form of a suspension of the powder in methanol. This medium was chosen due to better dispersibility of the carbon powder as compared to water. Measurements were carried out under controlled conditions, at a constant temperature of $20^{\circ} \mathrm{C}$.

In order to estimate the changes in the occurrence of $\mathrm{sp}^{2}$ and $\mathrm{sp}^{3}$ hybridization of carbon bonds, Raman spectroscopy was used. This was possible by analyzing the change in the characteristic $D$ and $G$ peak positions as well as the ratio between the surface areas $\left(\mathrm{I}_{\mathrm{d}} / \mathrm{I}_{\mathrm{g}}\right)$. Raman measurements were performed with a T-64000 Yobin-Yvon spectrometer using $514.5 \mathrm{~nm}$ argon ion laser light. The Raman spectra were fitted using Gauss-Lorentz curves. Studies of X-ray photoelectron spectroscopy (XPS) were carried out using ESCALAB-210 system (VG Scientific, UK) equipped with non-monochromatic $\mathrm{Al}(\mathrm{Ka}=1486.6 \mathrm{eV})$. XPS was used as an addition to the studies by means of Raman spectroscopy to determine the amount of $\mathrm{sp}^{2}$ and $\mathrm{sp}^{3}$ hybridized carbon bonds. C1s peak, characteristic of carbon-carbon bond energy of $284.8 \mathrm{eV}$, was analyzed.

\subsection{Experiment planning using Taguchi method}

Taguchi method is a combination of statistical techniques used in empirical research. It requires fewer experiments to examine all levels of all input parameters, and it filters certain effects due to statistical variation. Taguchi method may determine the parameters of an experiment having the smallest variation under optimum condition. Variability can be expressed by the ratio of signal to noise $(\mathrm{S} / \mathrm{N})$. The experimental condition having the maximum $\mathrm{S} / \mathrm{N}$ ratio is considered to be an optimum condition as the variation characteristics is inversely proportional to the ratio of $\mathrm{S} / \mathrm{N}[11,12]$. In the presented study, a Taguchi design (L9 $(4 \times 3)$ 
orthogonal array) was used to assess the effects of mechanical milling parameters on the mean particle size of the milled powders. Table 1 shows the process parameters and their levels. In this study, $\mathrm{S} / \mathrm{N}$ ratio was calculated using the "smaller is better" approach [13, 14]:

$$
E t a=-10 \log _{10}\left(\frac{1}{n} \sum_{i=1}^{n} y_{i}^{2}\right) \rightarrow \max
$$

where: $\mathrm{n}$ - number of observations, $\mathrm{y}_{\mathrm{i}}$ - value of i-th factor (mean particle size).

Table 1. Levels of milling process parameters.

\begin{tabular}{cccc}
\hline Parameter & Level 1 & Level 2 & Level 3 \\
\hline \hline Milling time $(\mathrm{h})$ & 1 & 5 & 10 \\
Rotational speed $(\mathrm{rpm})$ & 100 & 300 & 600 \\
Amount of liquid $(\mathrm{mL})$ & 0 & 2 & 10 \\
Ball to powder ratio & $5 / 1$ & $10 / 1$ & $20 / 1$ \\
\hline
\end{tabular}

\section{Results and discussion}

\subsection{Initial powders}

Powders produced using MW/RF PACVD method take a form of flakes with irregular edges, often with visible cracks which are a result of residual stress (Fig. 1).

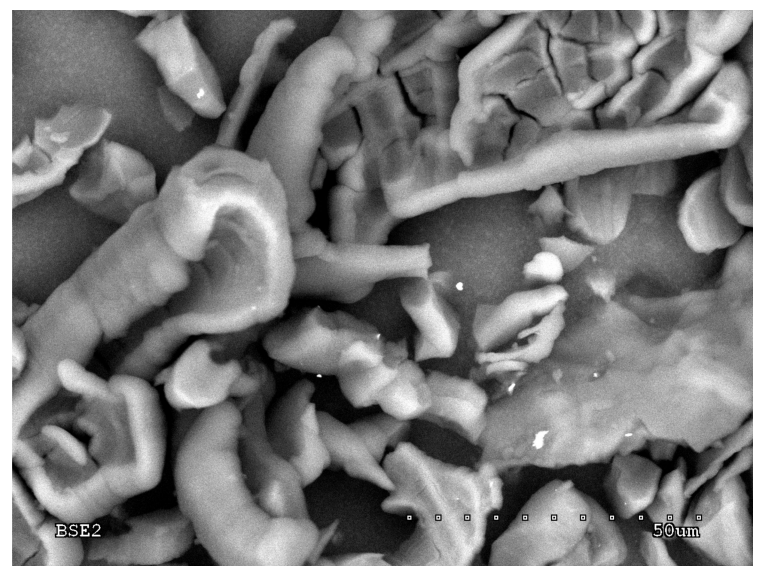

Fig. 1. Morphology of carbon powder obtained using MW/RF PACVD method.
They are characterized by very wide size distribution. Fig. 2 shows that the size of individual particles can vary from tens to up to $100 \mu \mathrm{m}$. These values can reach hundreds of microns if considering that carbon powders are very likely to form conglomerates.

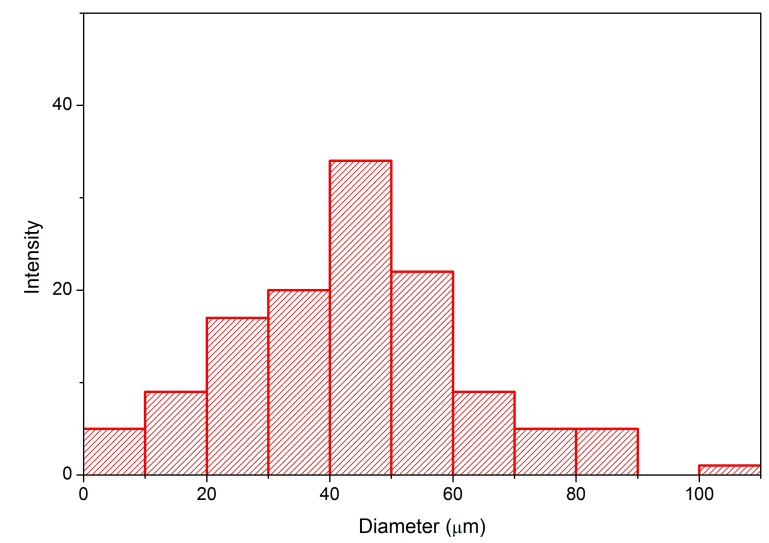

Fig. 2. Size distribution of carbon powder obtained using MW/RF PACVD method.

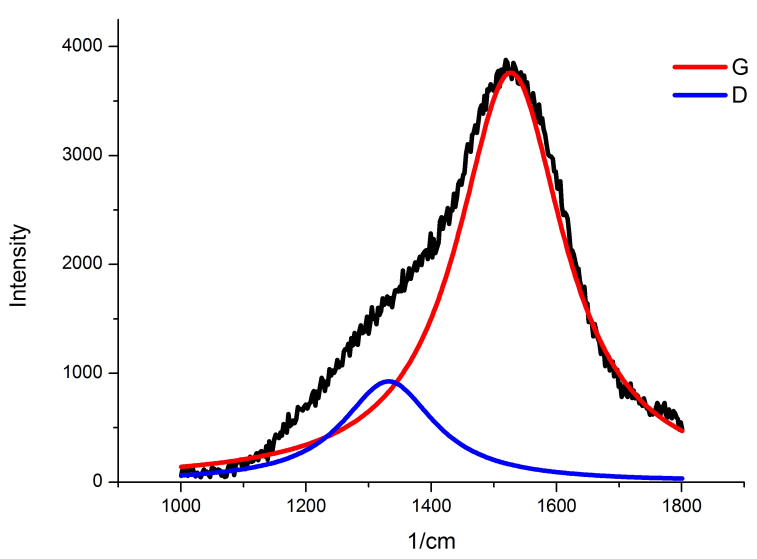

Fig. 3. Raman spectrum of carbon powder obtained using MW/RF PACVD method.

Fig. 3 presents a Raman spectrum of a powder produced using the described method. The deconvolution was done in two characteristic peaks, $\mathrm{D}$ and $\mathrm{G}$, located at positions $1331 \mathrm{~cm}^{-1}$ and $1526 \mathrm{~cm}^{-1}$, respectively. These peaks are referred to in the literature as a peak derived from the disordered phase (D) and a peak derived from $\mathrm{sp}^{2}$ hybridized bonds $(G)$ [15]. Based on the analysis of the spectrum it can be noticed that it is typical of 
carbon DLC coatings and the powder presents a similar phase composition [16].

Moreover, the shape of the spectrum and the ratio of $I_{D} / I_{G}$ suggests that the powder is composed of amorphous hydrogenated carbon $(\mathrm{a}-\mathrm{C}: \mathrm{H})$ with a high content of $\mathrm{sp}^{2}$ hybridized bonds [17].

\subsection{Main effects}

The analysis of variance (ANOVA) was used to distinguish the significant factors from the insignificant ones. The mean particle size results and $\mathrm{S} / \mathrm{N}$ ratios were used in the statistical evaluation and the results are presented in Tables 2 and 3, respectively.

Carbon powders subjected to milling showed various mean particle sizes, which was directly connected to milling conditions. The biggest reduction in size was obtained for the experiment number $8(0.48 \mu \mathrm{m})$. Experiment No. 1, in turn, produced the least modified powders. As can be seen in Fig. 4 which compares the obtained results, not only did the particle size reduce but also its distribution was narrowed which can be connected with the higher uniformity of the powders.

Clear changes in morphology can be seen compared to untreated powder. As shown in Fig. 5, the flake-like shape is transformed into small, more uniform in size grains that have sharper and more even edges. It can be attributed to two phenomena occurring simultaneously during milling: compression and shearing.

According to ANOVA analysis the most significant factor influencing the size of particles is the milling time ( $70.5 \%$ of contribution). Other parameters, as seen in Table 3, were determined as much less significant. Fig. 6 shows the main effects of these parameters for $\mathrm{S} / \mathrm{N}$ ratios for each level of the parameters. The average $\mathrm{S} / \mathrm{N}$ ratio values, calculated for each factor at a given level, allow establishing of the best levels. Regardless of the type of response, the $\mathrm{S} / \mathrm{N}$ ratio analysis is always interpreted in the same way; the larger the $\mathrm{S} / \mathrm{N}$ ratio the better [11].

For the milling speed parameter, the best level for particle size reduction was $600 \mathrm{rpm}$. Greater milling speeds provided higher energy in the
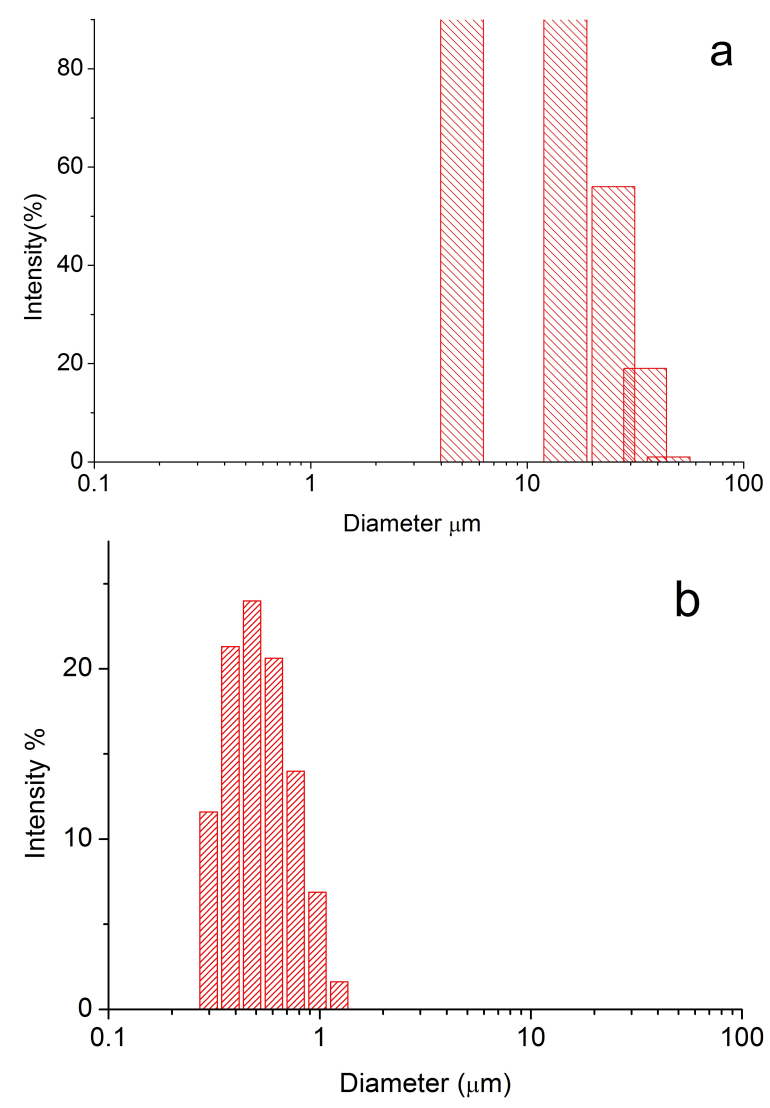

Fig. 4. Comparison of particle size distribution of the powders modified in (a) process 1 and (b) process 8 .

rotational movement of the mill and higher energy between the balls and the ball milling bowl, which improved the deformation and fracture of the carbon powder particles. Thus, the reduction of the particle size was also improved. However, there are certain limitations to the maximal speed that should be employed. Above a critical speed, the balls are pinned to the inner walls of the bowl and do not fall down to exert any impact force. Therefore, the maximal speed should be just below this critical value so that the balls would be able to fall down from the maximal height to produce the maximal collision energy.

Milling time was the most significant factor and the best results were obtained at 10 hours of milling. As a general rule it can be assumed, that at steady state conditions the gradual reduction of particle size is achieved over longer periods of time. 
Table 2. Taguchi L9 design and mean particle size.

\begin{tabular}{ccccccc}
\hline $\begin{array}{c}\text { Experiment } \\
\text { numer }\end{array}$ & $\begin{array}{c}\text { Milling speed } \\
(\mathrm{rpm})\end{array}$ & $\begin{array}{c}\text { Milling time } \\
(\mathrm{h})\end{array}$ & $\begin{array}{c}\text { Amount of } \\
\text { water }(\mathrm{mL})\end{array}$ & $\begin{array}{c}\text { Ball to powder } \\
\text { ratio }\end{array}$ & $\begin{array}{c}\text { Mean particle size } \\
(\mu \mathrm{m})\end{array}$ & $(\mathrm{S} / \mathrm{N})$ \\
\hline \hline 1 & 100 & 1 & 0 & 5 & 13.57 & -22.7 \\
2 & 100 & 5 & 2 & 10 & 10.56 & -20.5 \\
3 & 100 & 10 & 10 & 20 & 4.03 & -12.1 \\
4 & 300 & 1 & 2 & 20 & 0.98 & 0.2 \\
5 & 300 & 5 & 10 & 5 & 7.75 & -17.8 \\
6 & 300 & 10 & 0 & 10 & 0.77 & 2.3 \\
7 & 600 & 1 & 10 & 10 & 0.61 & 4.4 \\
8 & 600 & 5 & 0 & 20 & 0.48 & 6.4 \\
9 & 600 & 10 & 2 & 5 & 0.87 & 1.2 \\
\hline
\end{tabular}

Table 3. Results of analysis of variance for the parameters.

\begin{tabular}{cccc}
\hline Parameter & Sum of squares & Mean of squares & Contribution (\%) \\
\hline \hline Milling time & 761.8 & 380.9 & 70.5 \\
Rotational speed & 90.9 & 45.5 & 8.4 \\
Amount of liquid & 22.5 & 11.2 & 2.1 \\
Ball to powder ratio & 205.9 & 103.0 & 19.0 \\
\hline
\end{tabular}

However, it depends on the type of a mill used, as high energy mills may require shorter times of modification in order to avoid negative results of prolonged milling at high speeds.

The role of water as anti-agglomeration medium was opposite to initially intended. It can be noticed that with increasing the amount of water, carbon particles showed higher mean diameter values. This can be contributed to the fact that carbon powders are generally hydrophobic and do not easily dilute in water, therefore, they tend to form larger groups of particles.

Ball to powder ratio results prove, as it was in case of rotational speed, that energy input into a sample affects directly the obtained particle size. The optimum ratio for the smallest particles was 20:1. At a high ball to powder ratio the mean free path of the milling balls decreases due to an increase in the weight rate of the balls, and the number of collisions per unit time increases. Eventually, more energy is transferred to the powder particles resulting in a faster milling process.

\subsection{Verifying of optimal conditions}

On the basis of the analysis of $\mathrm{S} / \mathrm{N}$ ratios presented in Fig. 6, the optimal condition can be chosen for achieving the smallest particle size. The highest $\mathrm{S} / \mathrm{N}$ values corresponding to optimal parameters are presented in Table 4.

Table 4. Optimal conditions for achieving the smallest particle size.

\begin{tabular}{cc}
\hline Parameter & Value \\
\hline \hline Milling time (rpm) & 600 \\
Rotational speed (h) & 10 \\
Amount of liquid (mL) & 0 \\
Ball to powder ratio & $20 / 1$ \\
\hline
\end{tabular}

Milling process including the conditions presented above was performed in order to verify whether it would provide the smallest particle size. The result is presented in Fig. 7 showing both the size distribution and morphology of obtained powder. The obtained powder was characterized by an 


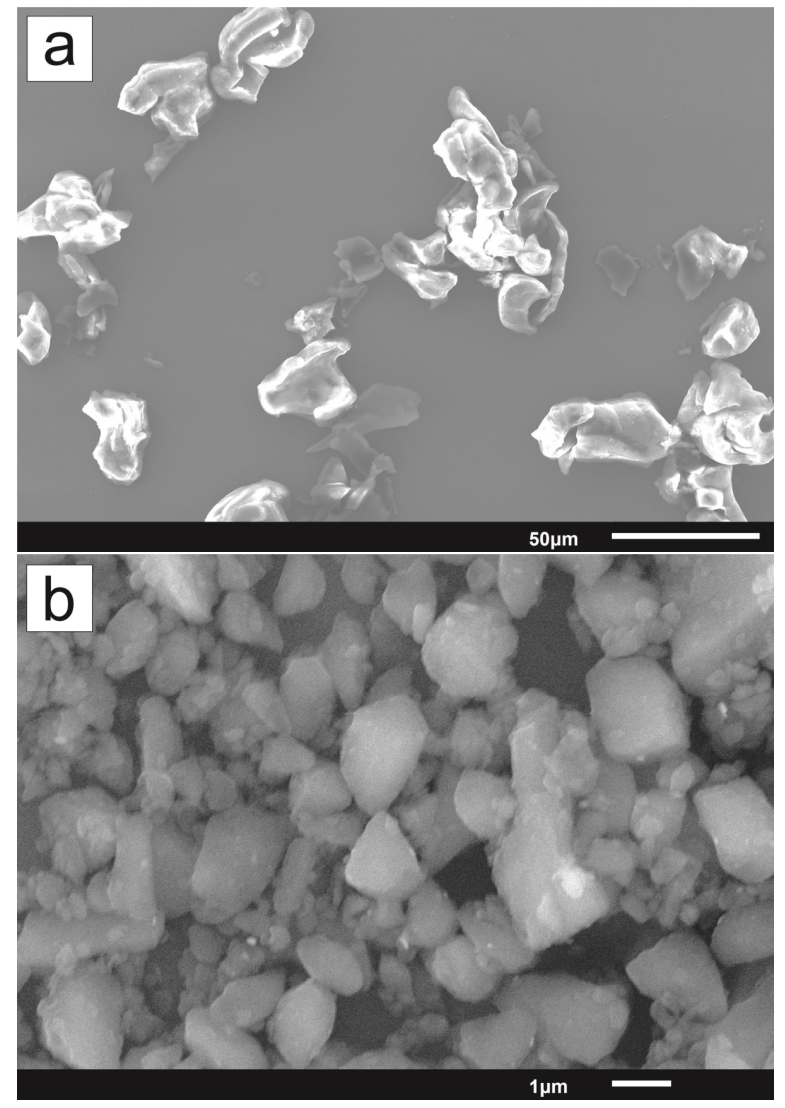

Fig. 5. Comparison of the results of milling corresponding to the two extreme values of $\mathrm{S} / \mathrm{N}$ ratio: (a) process 1 , (b) process 8 .

average particle size equal to $0.4 \mu \mathrm{m}$ compared to $0.48 \mu \mathrm{m}$ obtained in the preliminary study. In addition, $90 \%$ of the population of the powder showed a diameter in the range of 0.3 to $0.65 \mu \mathrm{m}$. Taguchi experiment plan confirmed the effectiveness of this method of optimization.

\subsection{Analysis of changes in phase composi- tion}

Milling of powders not only influences their particle size and morphology but also changes their phase composition. Mostly influenced is the ratio between the content of $\mathrm{sp}^{2}$ and $\mathrm{sp}^{3}$ phases which can be expressed in $I_{d} / I_{g}$ ratio. This change is attributed mainly to increased temperature connected with energy delivered to the process. Therefore, the milling speed is one of the most important factors. In Fig. 8, the influence of speed on the $I_{d} / I_{g}$ is shown.
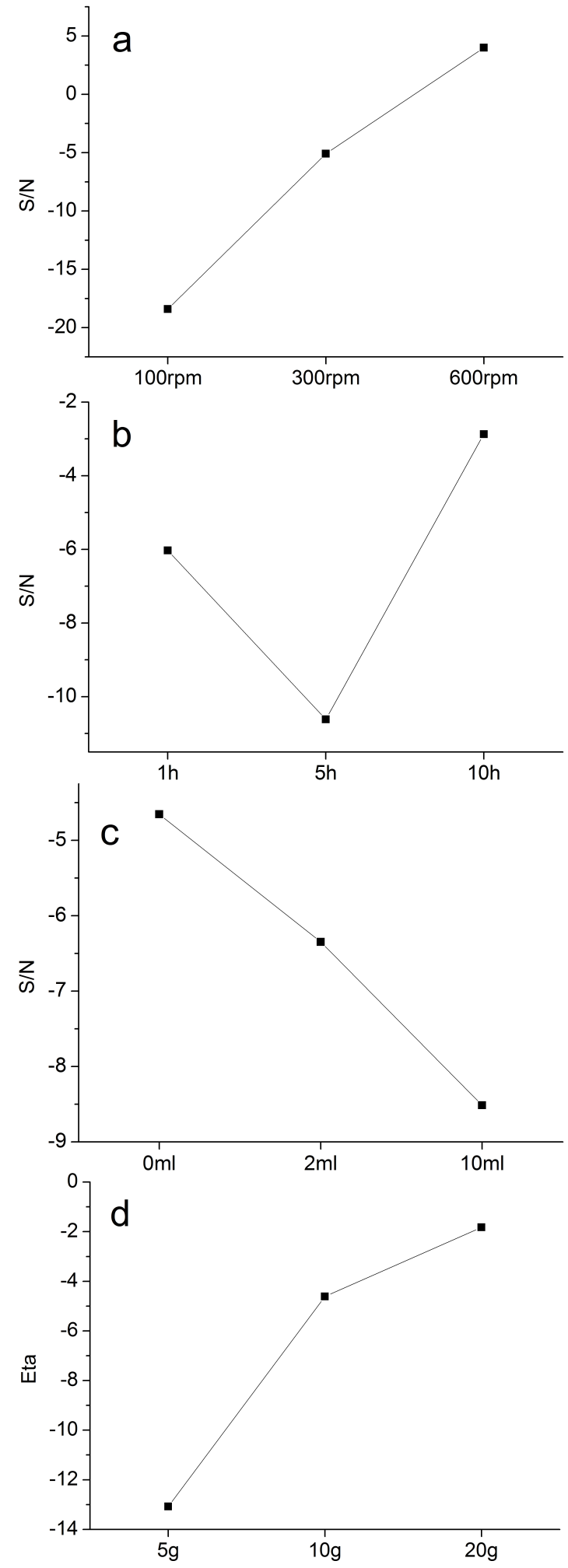

Fig. 6. Plots for the effects of the main parameters of the mechanical milling: (a) milling speed, (b) milling time, (c) amount of PCA and (d) ball to powder ratio. 

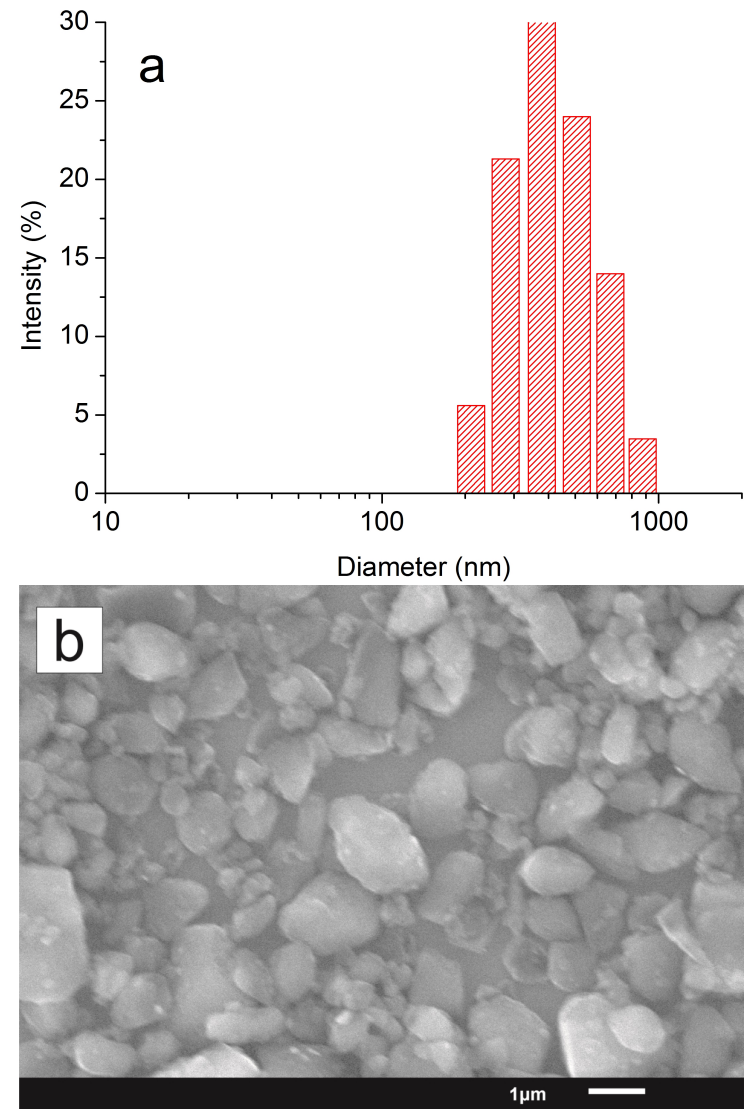

Fig. 7. Size distribution (a) and SEM (b) image presenting the morphology of carbon powder obtained under optimum conditions.

The growth of $I_{d} / I_{g}$ is suggested in the literature as the effect of reducing the contribution of $\mathrm{sp}^{3}$ hybridization bonds to $\mathrm{sp}^{2}$ bonds and increasing the carbon clusters with $\mathrm{sp}^{2}$ hybridization [15]. This also confirms the location of the $G$ peak, whose shift toward higher values may indicate a reduction of the share of $\mathrm{sp}^{3}$ bonds and $\mathrm{sp}^{2}$ cluster growth. Therefore, the carbon powder graphitization increases with the speed of milling which the powder is subjected to.

The process control agent in a form of a liquid is meant to decrease this effect due to better heat transfer from the powder, resulting in decreased graphitization. Additional processes were performed using optimal conditions described in Table 4 but with addition of methanol and distilled water.

A comparison of $\mathrm{sp}^{2}$ bond content, using the analysis of $\mathrm{C} 1 \mathrm{~s}$ peak characteristic of

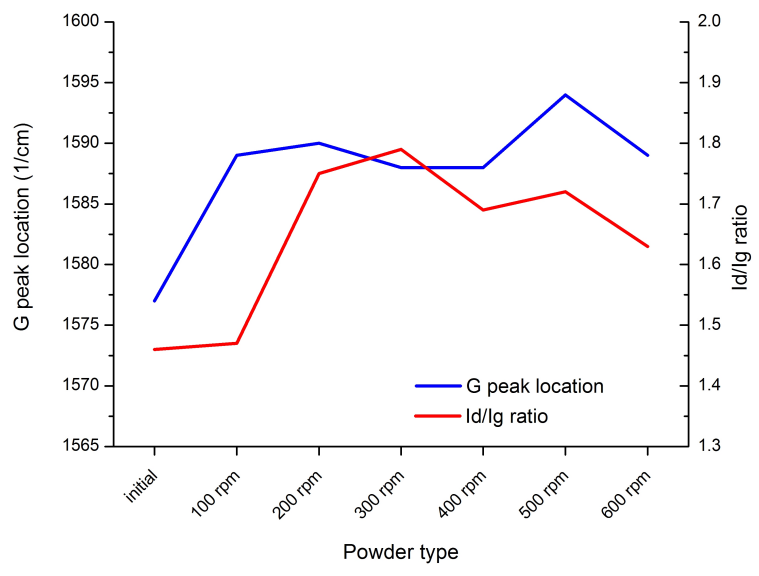

Fig. 8. Changes in $G$ peak location and $I_{d} / I_{g}$ ratio of carbon powder subjected to milling at various rotational speeds.

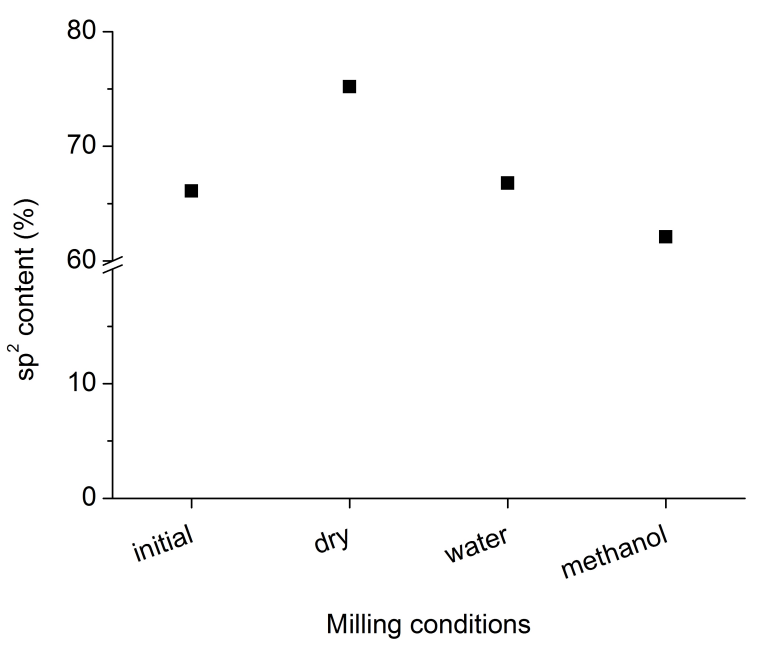

Fig. 9. Comparison of $\mathrm{sp}^{2}$ phase content in initial carbon powders and the powders milled at optimum conditions at the presence of process controlling agents (water and methanol).

carbon-carbon bond energy of $284.8 \mathrm{eV}$, measured using XPS method is shown in Fig. 9 [18]. It can be seen that dry milling leads to increased $\mathrm{sp}^{2}$ content, whereas introducing water or methanol to the process reduces this effect.

\section{Conclusions}

In this study, the main mechanical milling parameters, including the process control agent, milling speed, milling time and ball to powder 
weight ratio were analyzed by applying a Taguchi design (L9 $(4 \times 3))$. The experimental results indicated that the effect of milling time on particle size and powder morphology was more significant ( $70.5 \%$ contribution) than other milling parameters. The main milling parameters for obtaining the smallest particle size were optimized at the levels of: $10 \mathrm{~h}$ - milling time, $600 \mathrm{rpm}$ - milling speed, and 20:1 - ball to powder ratio. Additional milling process experiments were carried out at the optimum conditions, after which the obtained carbon powder had the mean particle size of $0.4 \mu \mathrm{m}$. In order to analyze the influence of process controlling agent on the changes in phase composition of powders during milling, additional processes were performed using water and methanol under optimum conditions. It was shown that using both liquids led to reduction of graphitization process which took place when the powder was subjected to dry milling.

\section{References}

[1] Ewsuk K.G., Gogotsi Y., Ceram. Trans., 190 (2006), 238.

[2] Shenderova O., Gruen D., Ultrananocrystalline Diamond: Synthesis, Properties and Applications, William-Andrew Publisher, New York, 2006.

[3] Mitura K., Karczemska A., Niedzielski P., GRABARCZYK J., KACZOROWSKI W., LOUdA P., MITURA S., Int. J. Nanomanuf., 2 (2008), 29.

[4] PuZyr A.P., Neshumayev D.A., Bondar V.S., Dolmatov V.YU., Shugalei I.V., Dubyago N.P., TARSKIKH S.V., MAKARSKAYA G.V., The Influence of Detonation Nanodiamond Powder on Blood Cells, in: LEE J., Novikov N. (Eds.), Innovative Superhard Materials and Sustainable Coatings for Advanced Manufacturing, Springer, 2005, p.155.
[5] SRIVAstava S.K., Vankar V.D., Kumar V., Thin Solid Films, 515 (2006), 1552.

[6] Ahmad B., Riaz M., Ahmad M., Nawaz S., AhMAD S., Mater. Lett., 62 (2008), 3367.

[7] Solarska K., Gajewska A., Kaczorowski W., Bartosz G., Mitura K., Diam. Relat. Mater, 21 (2012), 107.

[8] Batory M., Batory D., GrabarczyK J., KaCzorowski W., Kupcewicz B., Mitura K., NAsti T.H., Yusuf N., NiedZIElski P., J. Nanosci. Nanotechno., 12 (2012), 9037.

[9] CzerniaK-Reczulska M., Niedzielski P., BALCERCZYK A., BARTOSZ G., KAROWICZ-BILINSKA A., Mitura K., J. Nanosci. Nanotechno., 10 (2010), 1065.

[10] TAguchi G., System of experimental design, UNIPUB/Kraus International Publications New York, 1987.

[11] PARK K.S., Kim H.G., KIM Y.H., PARK C.H., KIM K.D., Chem. Eng. Res. Des., 89 (2011), 2389.

[12] Alamolhoda S., Heshmati-Manesh S., Ataie A., Adv. Powder Technol., 23 (2012), 343.

[13] Akhgar B.N., Pazouki M., Ranjbar M., HosSeinnia A., Salarian R., Chem. Eng. Res. Des., 90 (2012), 220.

[14] Zhang F.L., Zhu M., Wang C.Y., Int. J. Refract. Met. H., 26 (2008), 329.

[15] Ferrari A.C., Robertson J., Phys. Rev. B, 61 (2000), 14095.

[16] Cui W.G., Lai Q.B., Zhang L., Wang F.M., Surf. Coat. Tech., 205 (7) (2010), 1995.

[17] Chu P.K., Li L., Mater. Chem. Phys., 96 (2 - 3) (2006), 253.

[18] Tai F.C., LeE S.C., Wei C.H., Tyan S.L., Mater. Trans., 47 (2006), 1847. 